Article

\title{
Analysis and Optimization of Power Supply Structure Based on Markov Chain and Error Optimization for Renewable Energy from the Perspective of Sustainability
}

\author{
Xiaomin $\mathrm{Xu}{ }^{1}{ }^{1 *}$, Dongxiao Niu ${ }^{1}$, Jinpeng Qiu ${ }^{1}$, Peng Wang ${ }^{2}$ and Yanchao Chen ${ }^{3}$ \\ 1 Research Institute of Technology Economics Forecasting and Assessment, \\ School of Economics and Management, North China Electric Power University, Beijing 102206, China; \\ niudx@ncepu.edu.cn (D.N.); 1142206134@ncepu.edu.cn (J.Q.) \\ 2 Economic Research Office, Shaanxi Electric Power Design Institute Co., Ltd., \\ China Energy Construction Group, Xi'an 710054, China; wangpeng.jiejie@163.com \\ 3 Nanning Power Supply Company, Guangxi Power Grid, Nanning 530000, China; upermaxyc@126.com \\ * Correspondence: xuxiaomin0701@126.com or xuxm@ncepu.edu.cn; Tel.: +86-10-6177-3079
}

Academic Editor: Kannan Govindan

Received: 5 January 2016; Accepted: 21 June 2016; Published: 7 July 2016

\begin{abstract}
With the rapid development of renewable energy, power supply structure is changing. However, thermal power is still dominant. With the background in low carbon economy, reasonable adjustment and optimization of the power supply structure is the trend of future development in the power industry. It is also a reliable guarantee of a fast, healthy and stable development of national economy. In this paper, the sustainable development of renewable energy sources is analyzed from the perspective of power supply. Through the research on the development of power supply structure, we find that regional power supply structure development mode conforms to dynamic characteristics and there must exist a Markov chain in the final equilibrium state. Combined with the characteristics of no aftereffect and small samples, this paper applies a Markov model to the power supply structure prediction. The optimization model is established to ensure that the model can fit the historical data as much as possible. Taking actual data of a certain area of Ningxia Province as an example, the models proposed in this paper are applied to the practice and results verify the validity and robustness of the model, which can provide decision basis for enterprise managers.
\end{abstract}

Keywords: renewable energy; power supply structure prediction; Markov analysis; error optimization; optimal adjustment strategy

\section{Introduction}

With the development of the economy, the consumption of primary energy in China grows more quickly: The emission, pollutants and environmental deterioration caused by primary energy consumption are increasing. The contradiction between economic development and environmental protection have become increasingly prominent. Against the backdrop of exhausted traditional fossil fuels and environmental deterioration, renewable energy has been particularly favored by countries all over the world for its environmental friendliness, low pollution and regenerative ability [1]. Under With the encouragement and support of national policy, renewable energy power generation in China has developed rapidly over the past decade. So far, we have the largest scale and fastest-growing wind power in global comparison. By the end of 2013, wind power-installed capacity in China reached 91.7446 million $\mathrm{kW}$, and wind power generation reached 140 billion $\mathrm{kWh}$. Meanwhile, China is also a major solar power country. Up to the end of 2013, the solar power installed capacity reached 
14.79 million $\mathrm{kW}$, and solar power generation reached 8.7 billion $\mathrm{kWh}$. In addition, nowadays, China is actively studying the exploitation and utilization of biomass energy, geothermal energy, ocean energy and other renewable energy resources [2-4].

With the rapid development of renewable energy, power supply structure is changing. However, thermal power is still dominant, and the proportion of use is too large. China's thirteenth "Five-Year Plan" [5] clearly pointed out that we should vigorously develop renewable energy and substantially increase the proportion of renewable energy. Study of the prediction and optimization of power supply structure is not only conducive to a short period of economic development, but also related to the country's stable and sustainable development [6]. Therefore, optimizing the power supply structure and building a safe, stable, economical and clean power supply system has practical significance. To deeply grasp the future development of renewable energy in addition to the accurate prediction of renewable energy power generation, it is also necessary to understand the structural proportion of renewable energy and trends of future development. The twelfth "Five-Year Plan" [7] in China clearly stated that the proportion of non-fossil energy consumption in primary energy consumption will reach $11.400 \%$ in 2015 . The importance of renewable energy will be further enhanced during China's energy structure adjustment. The optimization of energy structure is related to the sustainable development of economy and society [6]. Therefore, the prediction of the power supply structure has great significance. There are many methods for structure development prediction, such as the moving average method, the regression analysis method, the exponential smoothing method, grey theory [6], the neural network model [8], the Markov model [9] and so on. The Russian mathematician Markov proposed the Markov process in the study of random variables sequences; and subsequently developed the concept and principle of the Markov chain [10]. So far, Markov modelling has already formed a perfect theoretical system, and has satisfied prediction accuracy for non-aftereffect sequences. The Markov prediction method takes the state and the state transition of a dynamic system as the study object, and it requires recent data to predict the future instead of continuous historical data [11]. Through the research on the development of renewable energy structures, we can see that if the state of the study object follows a certain condition, it will eventually reach a stable state through the state transition over time, and the final state has nothing to do with the initial state. The regional renewable energy development mode accords with dynamic characteristics, so there must exist a Markov chain before the final equilibrium state [9]. This model has been widely used in many fields, such as image processing, communication, medical treatment, etc., and has achieved excellent results in the prediction of energy structure [12], power consumption structure [13], passenger traffic structure [14] and other areas. Therefore, using the Markov model to study the development of regional renewable energy structure is in line with the law of its development.

Based on the above analysis and the status of the development of renewable energy, this paper applies Markov structure transition analysis for power supply structure development forecasting to optimize regional power supply structure. As determining the transition probability of Markov model is the main difficulty in model research, an optimization model is established to reduce the square error sum of the actual probability matrix and the calculated probability matrix in prediction model and make the result fit the historical data as much as possible. Accordingly, related technology strategies, management strategies and policies are proposed to increase the proportion of renewable energy power generation. The validity of the model is verified by the example of renewable energy data in a certain area of Ningxia province. Determining the structure of the future renewable energy development through the model will provide decisive support for the construction planning of regional power grids.

\section{Basic Theory}

\subsection{Markov Property, Markov Process and Markov Chain}

Markov property is also known as non-aftereffect property, and specifically at a certain moment $t$, the state of the process is known. At the moment $t_{1}>t$, the conditional probability distribution has nothing to do with the state at the time $t_{1}$ and is only related to the state at the time $t$. 
The probability distribution function is used to describe the Markov property, and it can be expressed as follows [9]:

The state space of the random process $\{X(t), t \in T\}$ is $I$. If at any moment $n$ of time $t$, that is $t_{1}<t_{2}<\cdots<t_{n}, n \geqslant 3, t_{i} \in T$, and under the conditions of $X\left(t_{i}\right)=x_{i}, x_{i} \in I, i=1,2, \cdots, n-1$, the conditional probability distribution function of $X\left(t_{n}\right)$ is equal to the conditional distribution function of $X\left(t_{n}\right)$ under the condition of $X\left(t_{n-1}\right)=x_{n-1}$. Namely:

$$
\begin{aligned}
& P\left\{X\left(t_{n}\right) \leqslant x_{n}\left|X\left(t_{1}\right)=x_{1},\right| X\left(t_{2}\right)=x_{2}, \cdots, \mid X\left(t_{n-1}\right)=x_{n-1}\right\} \\
& =P\left\{X\left(t_{n}\right) \leqslant x_{n} \mid X\left(t_{n-1}\right)=x_{n-1}\right\}, x_{n} \in R
\end{aligned}
$$

The process $\{X(t), t \in T\}$ has the Markov property, and is called a Markov process. In general, a Markov process with discrete time and discrete state is called a Markov chain. It is described by mathematical language as follows.

The state space of the random process $\{X(t), t \in T\}$ is $I$. For any $m$ non-negative integer $n_{1}, n_{2}, \cdots, n_{m}\left(0 \leqslant n_{1}<n_{2}<\cdots n_{m}\right)$ and any natural number $k$ as well as any $i_{1}, i_{2}, \cdots, i_{m}, j \in I$, it satisfies the following conditions:

$$
\begin{aligned}
& P\left\{X\left(n_{m}+k\right)=j \mid X\left(n_{1}\right)=i_{1}, X\left(n_{2}\right)=i_{2}, \cdots, X\left(n_{m}\right)=i_{m}\right\} \\
& =P\left\{X\left(n_{m}+k\right)=j \mid X\left(n_{m}\right)=i_{m}\right\}
\end{aligned}
$$

The stochastic process $\{X(t), t \in T\}$ is called Markov chain.

\subsection{Transition Probability}

The state space of the random process $\{X(t), t \in T\}$ is $I$. Under the condition of being in the state $i$ at the time $m, n$-step transition probability that the system is transferred to the state $j$ through $n$ steps is called the $n$-step transition probability of the time $m$, as shown in the equation

$$
p_{i j}^{(n)}(m)=P\left\{X_{m+n}=j \mid X_{m}=i\right\}, i, j \in I
$$

In particular, when $n=1, p_{i j}^{(1)}(m)$ can be called $p_{i j}$, and called it the Markov chain transition probability.

The transition probability $p_{i j}^{(n)}(n)$ has the following two properties:

$$
\begin{gathered}
p_{i j}^{(n)}(n) \geqslant 0, i, j \in I \\
\sum_{j \in I} p_{i j}^{(n)}(m)=1, i \in I
\end{gathered}
$$

The literature theorem shows that the $n$-step transition probability of a Markov chain meet the Chapman Kolmogorov equation, i.e., for any positive integer $h, l$, there are:

$$
p^{h+l}(n)=P^{(h)}(n) P^{(l)}(n+h)
$$

The next equation can be obtained through a recursive process:

$$
p^{(h)}=(p)^{h}
$$

From the Equation (7), a Markov transition matrix can be obtained directly by a one-step transition matrix, thus providing a simple transition probability calculation method. 


\subsection{The Ergodic Property of a Markov Chain}

The ergodic property of a Markov chain is that if the limit of a Markov chain transition probability exists and has nothing to do with $i$ it is:

$$
\lim _{k \rightarrow \infty} p_{i j}(k)=p_{j} ; i, j \in I
$$

Moreover, it can be proven that for any $i, j \in I ; i, j=1,2 \cdots N$, there must exist $p_{i j}(k)>0$. That is to say, Markov chain has ergodicity. In addition, limit distribution $\pi=\left(\pi_{1}, \pi_{2}, \cdots\right)$ is the unique solution of equations $\pi_{j}=\sum_{i=1}^{N} \pi_{i} p_{i j}$ (namely $\pi=\pi P$ ) under the $\pi_{j}>0, \sum_{j=1}^{N} \pi_{j}=1$-conditions [15].

\subsection{Error Optimization Transition Probability Matrix Estimation Method}

The determination method of the state transition probability matrix of Markov's prediction method has been a hot topic in research [16]. This paper introduces the error optimization idea to determine the transition probability matrix, making the error sum of squares of the probability matrix calculated by this model and the actual probability matrix reach the minimum, and establishing the optimization model.

Assuming that $\alpha(t)=\left(p_{t}(1), p_{t}(2), \cdots p_{t}(n)\right)(t=1,2, \cdots, m)$ is a probability vector of a system for the time $t$ in a certain state, the one-step status transition probability matrix is $P=\left(p_{i j}\right)_{n \times n}$. In fact, due to the changes of the objective environment, the one-step status for the transition probability matrix of an adjacent time is not the same, so there is a certain error between $\alpha(t+1)$ and $\alpha(t) P$. Based on the principle of the minimum sum of squared errors, the optimization model is established as in Equation (9):

$$
\begin{aligned}
& \min f(p)=\sum_{t=0}^{m-1}\|\alpha(t+1)-\alpha(t) P\| \|^{2}=\sum_{t=0}^{m-1}(\alpha(t+1)-\alpha(t) P)(\alpha(t+1)-\alpha(t) P)^{T} \\
& \text { s.t }\left\{\begin{array}{c}
\sum_{j=1}^{n} p_{i j}=1, i=1,2, \cdots n \\
p_{i j} \geqslant 0, j=1,2, \cdots n
\end{array}\right.
\end{aligned}
$$

\section{Case Study}

\subsection{Prediction of Power Supply Structure Based on the Optimized Markov Model}

Nowadays, the Markov model is a perfect theory system, and achieves good prediction accuracy in no-aftereffect sequence prediction. Based on the characteristics of Markov theory, in this study, the Markov model is applied to the prediction of the renewable energy development structure in a certain area of Ningxia. As the difficulty in the model study is the transition probability of the matrix's determination in the Markov prediction model, this paper aims to establish an optimized model to make the error sum of squares reach the minimum, and ensure that the model calculation results can fit the historical data as much as possible. Through access to information and analysis, we know that since 2009, the region's renewable energy power generation began to accelerate. Accordingly, this paper selected the power supply data from 2009 to 2014 as a basis data for the exemplary analysis of this case study. The annual electricity generation and power supply structure are shown in Figure 1 and Table 1. 

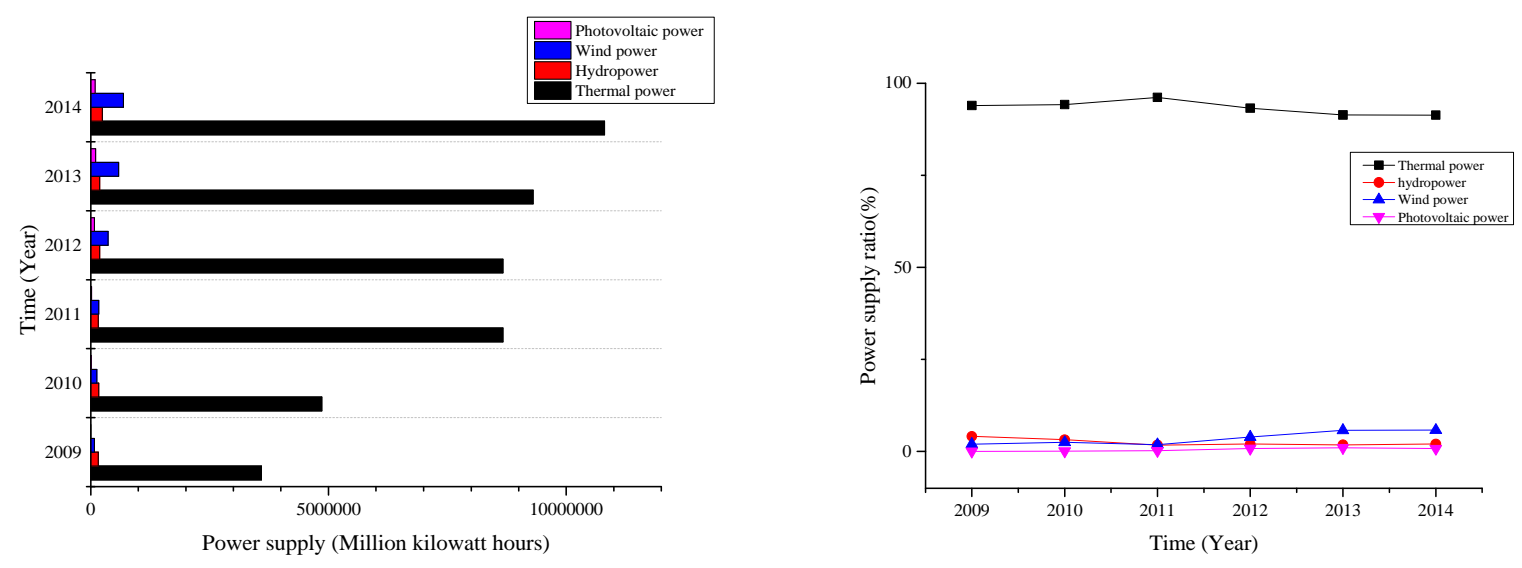

Figure 1. The chart of annual electricity generation and power supply ratio from 2009 to 2014 in Ningxia Province.

Table 1. Data form of power supply generation and structure from 2009 to 2014 in Ningxia Province.

\begin{tabular}{ccccccccc}
\hline \multirow{2}{*}{ Year } & \multicolumn{2}{c}{ Wind Power } & \multicolumn{2}{c}{$\begin{array}{c}\text { Photovoltaic Power } \\
\text { Generation }\end{array}$} & \multicolumn{2}{c}{ Hydropower } & \multicolumn{2}{c}{$\begin{array}{c}\text { Thermal Power } \\
\text { Generation }\end{array}$} \\
\cline { 2 - 9 } & $\begin{array}{c}\text { Electricity } \\
\text { (twh) }\end{array}$ & $\begin{array}{c}\text { Ratio } \\
(\mathbf{\%})\end{array}$ & $\begin{array}{c}\text { Electricity } \\
\text { (twh) }\end{array}$ & $\begin{array}{c}\text { Ratio } \\
\mathbf{( \% )}\end{array}$ & $\begin{array}{c}\text { Electricity } \\
\text { (twh) }\end{array}$ & $\begin{array}{c}\text { Ratio } \\
\text { (\%) }\end{array}$ & $\begin{array}{c}\text { Electricity } \\
\text { (twh) }\end{array}$ & $\begin{array}{c}\text { Ratio } \\
\text { (\%) }\end{array}$ \\
\hline 2009 & 358.810 & 1.976 & 15.710 & 0.001 & 7.550 & 4.113 & 0.0035 & 93.910 \\
2010 & 485.780 & 2.482 & 16.700 & 0.113 & 12.810 & 3.237 & 0.580 & 94.168 \\
2011 & 866.950 & 1.870 & 15.860 & 0.208 & 16.860 & 1.760 & 1.880 & 96.162 \\
2012 & 866.950 & 3.980 & 18.850 & 0.832 & 36.630 & 2.049 & 7.650 & 93.140 \\
2013 & 930.090 & 5.788 & 18.620 & 1.003 & 58.910 & 1.829 & 10.210 & 91.380 \\
2014 & 1080.500 & 5.820 & 24.300 & 0.783 & 68.840 & 2.054 & 9.260 & 91.343 \\
\hline
\end{tabular}

It can be seen from Figure 1 that, despite the increase in the amount of energy power generation, the proportion of thermal power is declining, while the proportion of renewable energy power generation is increasing (both regarding growth rate and general structure). In Table 1, the ratio of wind power and solar photovoltaic power generation increased from 2009 to 2014 in Ningxia. As there are less hydropower resources available and renewable energy power generation from other sources increase, the proportion of hydropower generated electricity quantities decreased. The proportion of thermal power remained above $90 \%$, but from observing the trend, we assume that the proportion will decrease.

Predicting the power supply structure in the region by using the Markov prediction model based on error optimization, and through the MATLAB software [17], we can obtain the transition probability matrix as follows:

$$
P=\left[\begin{array}{cccc}
0.7922 & 0 & 0 & 0.2078 \\
0.5329 & 0.2680 & 0.1575 & 0.0416 \\
0 & 0.0033 & 0.0844 & 0.9123 \\
0.0140 & 0.0051 & 0.0205 & 0.9605
\end{array}\right]
$$

According to the transition probability matrix and the Markov forecasting model, the prediction results of power supply structure are as shown in Table 2. Traditional Markov is selected as the contrast method. Setting the data from 2009 to 2015 as the test sample, and taking objective factors of the development of renewable energy sources (the environment, location, cost, etc.) into account, the predicted results obtained by the two methods are compared with the actual values. Thus, the relative errors are gained as shown in Figure 2. This paper selects the mean absolute percentage error index as quantitative evaluation of the prediction results. 
Table 2. The prediction results of the power supply structure in Ningxia Province from 2009 to 2020.

\begin{tabular}{|c|c|c|c|c|c|c|c|c|c|c|c|c|}
\hline & \multicolumn{3}{|c|}{ Wind Power } & \multicolumn{3}{|c|}{ Photovoltaic Power } & \multicolumn{3}{|c|}{ Hydropower } & \multicolumn{3}{|c|}{ Thermal Power } \\
\hline & $\begin{array}{l}\text { Actual } \\
\text { Value }\end{array}$ & Markov & $\begin{array}{c}\text { Error } \\
\text { Optimization } \\
\text { Markov }\end{array}$ & $\begin{array}{l}\text { Actual } \\
\text { Value }\end{array}$ & Markov & $\begin{array}{c}\text { Error } \\
\text { Optimization } \\
\text { Markov }\end{array}$ & $\begin{array}{l}\text { Actual } \\
\text { Value }\end{array}$ & Markov & $\begin{array}{c}\text { Error } \\
\text { Optimization } \\
\text { Markov }\end{array}$ & $\begin{array}{l}\text { Actual } \\
\text { Value }\end{array}$ & Markov & $\begin{array}{c}\text { Error } \\
\text { Optimization } \\
\text { Markov }\end{array}$ \\
\hline 2009 & 1.976 & 1.857 & 2.054 & 0.001 & 0.002 & 0.0012 & 4.113 & 4.136 & 3.9568 & 93.910 & 94.005 & 93.988 \\
\hline 2010 & 2.482 & 2.294 & 2.509 & 0.113 & 0.151 & 0.124 & 3.237 & 2.257 & 3.156 & 94.168 & 95.298 & 94.211 \\
\hline 2011 & 1.870 & 2.04 & 2.037 & 0.208 & 0.235 & 0.224 & 1.760 & 0.924 & 2.039 & 96.162 & 96.801 & 95.700 \\
\hline 2012 & 3.980 & 3.29 & 4.016 & 0.832 & 0.872 & 0.859 & 2.049 & 1.686 & 1.833 & 93.140 & 94.152 & 93.292 \\
\hline 2013 & 5.788 & 4.598 & 5.750 & 1.003 & 1.048 & 1.017 & 1.829 & 1.468 & 1.73 & 91.380 & 92.886 & 91.503 \\
\hline 2014 & 5.820 & 5.739 & 5.780 & 0.783 & 0.831 & 0.794 & 2.054 & 1.154 & 1.988 & 91.343 & 92.276 & 91.438 \\
\hline 2015 & 5.870 & 5.190 & 5.870 & 0.650 & 0.753 & 0.650 & 2.170 & 2.182 & 2.165 & 91.320 & 91.875 & 91.315 \\
\hline 2016 & & 4.250 & 6.271 & & 0.658 & 0.647 & & 2.873 & 2.165 & & 92.219 & 90.929 \\
\hline 2017 & & 4.710 & 6.582 & & 0.787 & 0.644 & & 2.439 & 2.153 & & 92.064 & 90.630 \\
\hline 2018 & & 4.618 & 6.712 & & 0.899 & 0.641 & & 2.677 & 2.144 & & 91.806 & 90.495 \\
\hline 2019 & & 5.663 & 6.798 & & 0.683 & 0.638 & & 2.820 & 2.152 & & 90.835 & 90.415 \\
\hline 2020 & & 4.520 & 7.013 & & 0.726 & 0.637 & & 2.623 & 2.149 & & 92.131 & 90.205 \\
\hline \multicolumn{3}{|c|}{ MAPE (\%) } & Markov of e & r opt & tion & \multicolumn{2}{|l|}{3.76} & \multicolumn{3}{|c|}{ Markov } & \multicolumn{2}{|r|}{14.81} \\
\hline
\end{tabular}


From Figure 2, we gather that the relative error of the optimized Markov model is smaller than that of a traditional Markov. Due to the volatility of renewable energy power generation, the prediction is more difficult. Compared to the stable output of thermal power, the forecast accuracy of renewable energy power generation is lower. Thus, thermal power prediction has the smallest error and the most stable trend. In terms of thermal power forecasting, the error of the two methods are both small and an advantage of the optimized Markov model is not obvious. Nevertheless, in terms of the renewable energy power supply structure prediction, the optimized Markov shows an absolute advantage. The traditional model has a larger error and error fluctuation range, whose maximum reached $100 \%$. In addition to the two abnormal points, the relative errors of the optimized Markov model in other years are controlled within $\pm 10 \%$. Meanwhile, the relative error is relatively smooth, which shows that the prediction performance of the proposed method is stable. Thus, the optimized Markov model is more suitable for the prediction of the power supply structure of renewable energy sources, and has better stability and robustness.

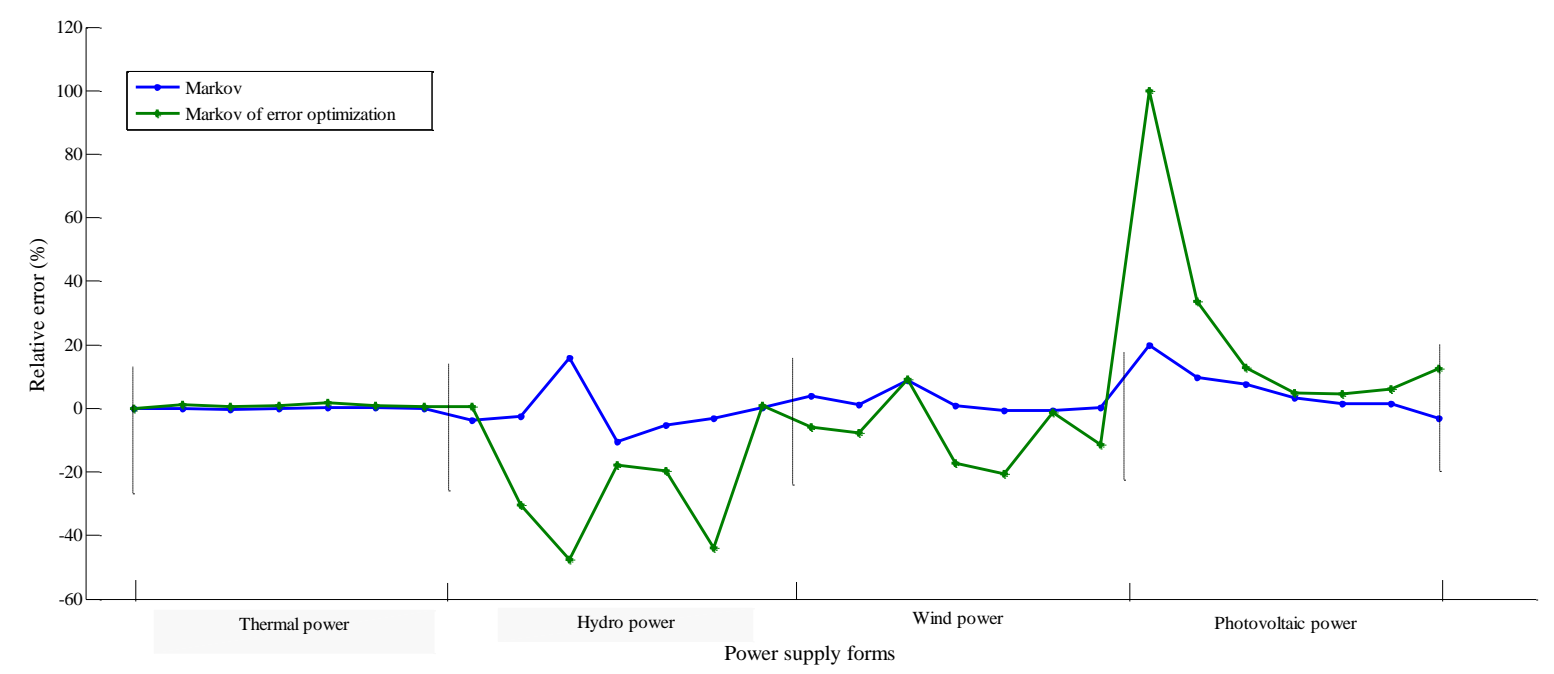

Figure 2. Relative error diagram of the two methods.

Based on the prediction results of the optimized Markov model, we can obtain the power supply structure of Ningxia Province from 2015 to 2020, as shown in Figure 3.

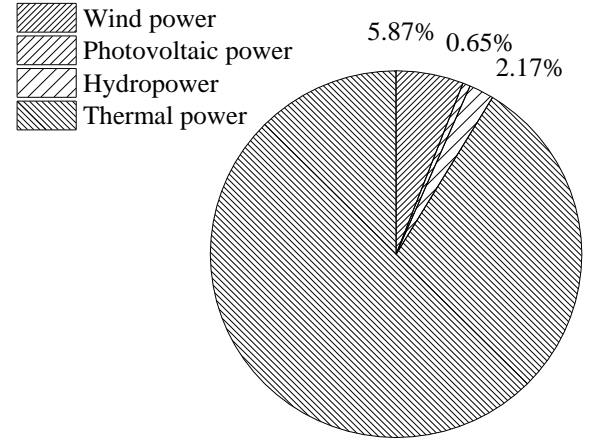

$91.32 \%$

(a)

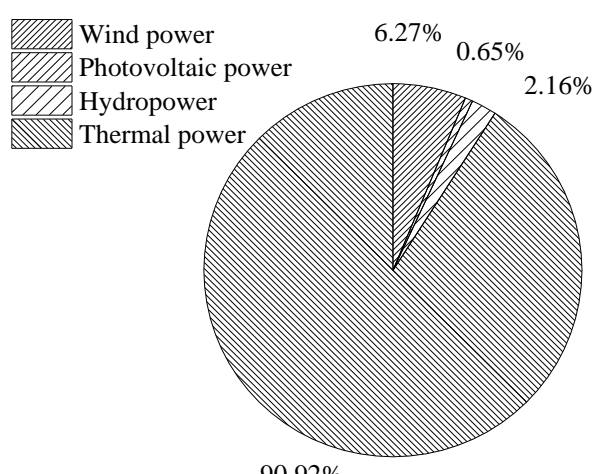

$90.92 \%$

(b)

Figure 3. Cont. 


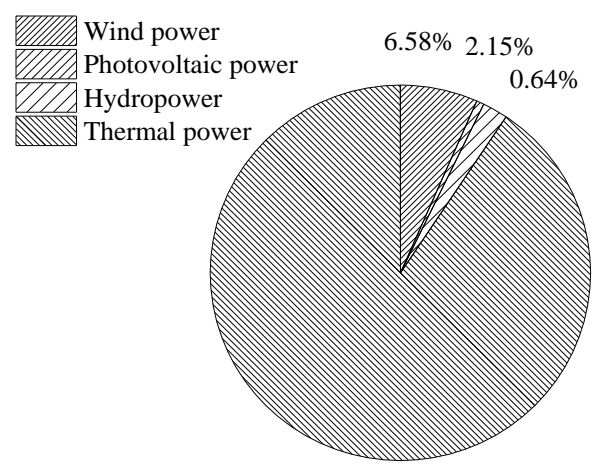

$90.62 \%$

(c)

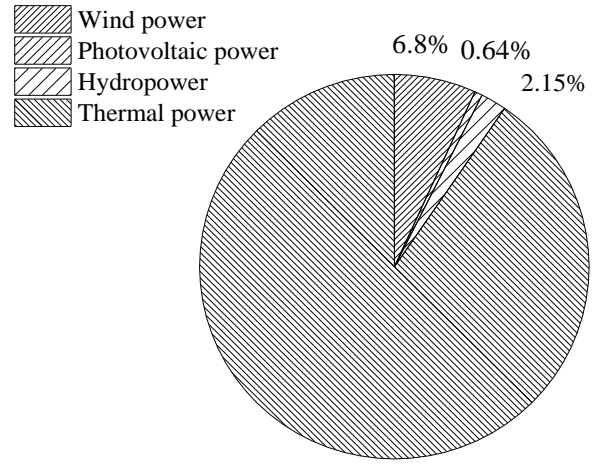

$90.41 \%$

(e)

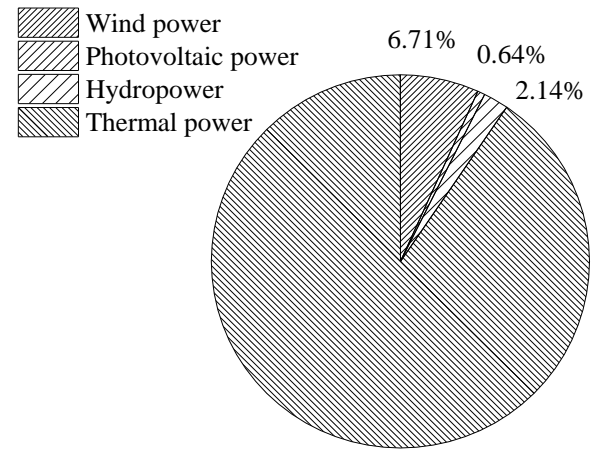

$90.5 \%$

(d)

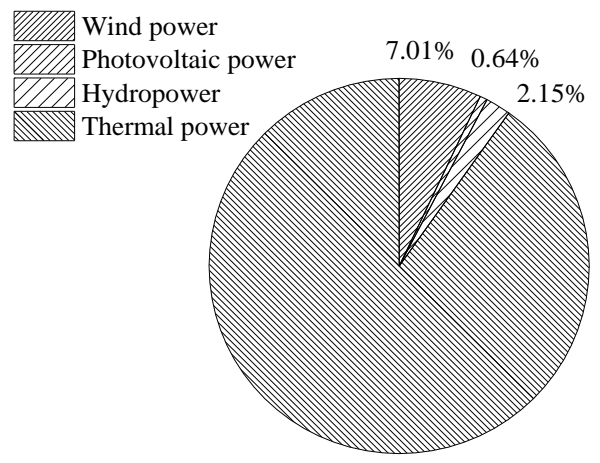

$90.2 \%$

(f)

Figure 3. The proportion of the power supply structure for the years 2015 (a); 2016 (b); 2017 (c); 2018 (d); 2019 (e); 2020 (f).

Based on the prediction results, the proportion of wind power consumption will continue to increase from 2015 to 2020, reaching 7.013\% in 2020. In the next five years, the region's installed capacity of solar photovoltaic power generation is small, and the proportion of photovoltaic power generation will remain relatively stable. The proportion of thermal power will still decrease and drop to $90.205 \%$ in 2020 .

\subsection{Analysis of the Equilibrium State of Regional Power Supply Structure}

On the basis of the transition probability matrix of the power supply structure, we can gain the balance of power structure system, i.e., that the probability of each state remains the same in the system. The balance state prediction results of the power supply structure are shown in Table 3 and Figure 4 .

Table 3. The balance state prediction results of the power structure in a certain area of Ningxia Province.

\begin{tabular}{ccccc}
\hline & Wind Power (\%) & $\begin{array}{c}\text { Photovoltaic Power } \\
\text { Generation (\%) }\end{array}$ & Hydropower (\%) & $\begin{array}{c}\text { Thermal Power } \\
\text { Generation (\%) }\end{array}$ \\
\hline Balance state & 7.644 & 0.634 & 2.111 & 89.611 \\
\hline
\end{tabular}




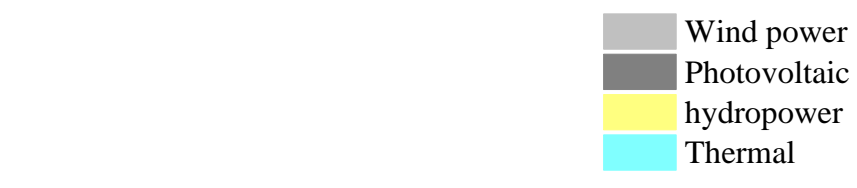

$89.61 \%$

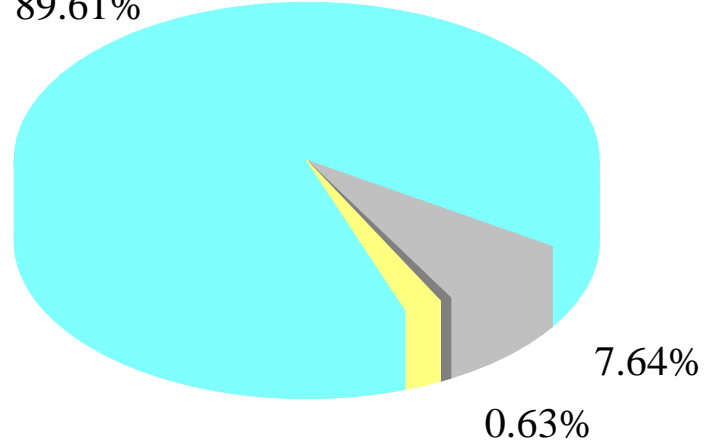

$2.11 \%$

Figure 4. The proportion of the power supply structure under the balance state.

The proportion prediction results of the power supply structure under the balance state display that the power supply structure will not change much in the future. Although the proportion of thermal power will decline gradually, the power structure dominated by thermal power will not change and thermal power will still occupy a large proportion in the short term due to its energy structure characteristics. In virtue of the further development of wind power technology and related supporting policies, the proportion of wind power will increase. The installed capacity development and the growth rate of solar photovoltaic power generation and hydropower will be relatively slow, with stable power supply structure. Finally, the proportion of wind power, photovoltaic power generation, hydropower, and thermal power generation under the balance state are $7.644 \%, 0.634 \%$, $2.111 \%, 89.611 \%$, respectively. The final equilibrium state is formed under the following objective influence of different energy sources.

Ningxia Province is the coal production base of China. Coal development in the Ning Dong region of Ningxia Province is strictly in accordance with national planning, which has better links in terms of natural conditions, coal size and market demand compared with other regions. Therefore, the thermal power resources in Ningxia Province are more abundant for large installed capacity. Although renewable energy technology continues to progress, thermal power will remain the region's major energy form in the future. Its coal based power supply structure is difficult to change in the short term.

Wind power generation has the advantage of not polluting the air, while the cost of construction unit is high. Also, it needs to pay attention to the city's wind resources and placement, which will directly affect the stability and cost performance of wind power generation. Ningxia Province, as one of the provinces with abundant wind energy resources, has 356 Million kilowatts wind energy resources for development. And the climate is suitable for the operation of wind turbines throughout the year. Therefore, the future proportion of wind energy generation in Ningxia Province will increase year by year.

Photovoltaic power generation has incomparable advantages: Solar energy resources are not exhausted and widely distributed. Silicon, as the main material of solar cells for photovoltaic power generation, can rely on an abundance of raw materials. Without mechanical rotating parts, photovoltaic power generation makes little noise and is stable. It also simple maintain and thus has low maintenance costs. Yet, it cannot achieve continuous power generation and is greatly affected by meteorological conditions. Moreover, the cost of a photovoltaic system is relatively high with system costs of 40,000-60,000 yuan/ $\mathrm{kW}$. In addition, the process of solar cells production will cause pollution. At present, most of the enterprises in Ningxia use metallurgical methods to produce the 
polycrystalline silicon required, and have high energy consumption and cause serious pollution. Besides, Ningxia photovoltaic power generation resources are in conflict with the distribution of land resources. These reasons make for the slow development of photovoltaic power generation in Ningxia Province.

Hydropower is clean and renewable energy. It has the advantage of low running costs and convenient power peaking, which is better for improving the utilization ratio of resources to comprehensive economic and social benefits. However, it can be greatly affected by climate and geographical location. Groundwater resources in Ningxia are small and have poor quality, and display great differences in distribution. Consequently, the development of hydropower is slow and lags behind the development of wind power.

\section{Optimization Adjustment Strategy for Power Supply Structure}

In view of the status of electric power supplies in Ningxia Province, combined with the development strategy of renewable electric reform as well as the thirteenth "Five-Year Plan" [5], the basic idea of power supply structure optimization in this paper is: clean energy priority, scientific utilization, energy conservation priority, double control and coordinated development. From the three aspects of technology, management and policy, this paper puts forward related strategies to promote the development of renewable energy and improve the proportion of power generation [18].

\subsection{Developing Renewable Energy Friendly Power Systems}

A renewable energy-friendly power system has three main features: a strong grid, flexible operation and advanced technology [19]. A strong grid is the basis and premise for the safe and stable operation and the rational allocation of resources of a power grid. Flexible operation refers to the flexible operation of a renewable energy-friendly power system, which adapts to the instability of renewable energy power, has a certain scale of flexible adjustment of power supply and can fully mobilize the demand side resources. Advanced technology means more advanced power system technology with intelligent renewable energy-capacity scheduling. In order to meet the demands of power grid dispatching and monitoring at all levels, it needs to construct grid dispatching decision support systems to achieve static, transient and dynamic analyses of security and early warning functions at the different stages of power grid planning, scheduling and real-time operation. It is crucial to optimize renewable power and conventional power units, make full use of load forecasting data and renewable energy power generation forecasting data, reasonably arrange power generation plans and realize the optimization of power grid dispatching.

\subsection{Rational Planning of Development Scale Power Grids and Renewable Energy Power}

The unbalanced planning of power grids and renewable energy power has always been the main factor restricting the access of renewable energy to the grid. For example, in September 2012, the National Energy Bureau has released a wind power development plan [20]. However, the development plan of the electric network obviously lags behind and renewable energy, especially the rapidly developing wind power, has far exceeded the power grid company's grid capacity. The future total scale of renewable energy power generation will have a larger growth for a period of time, and on-grid renewable energy power generation needs to be solved urgently. This calls for the coordination of power grid planning and renewable energy power supply, indicating that it must match the development of renewable energy power through rational planning of grid [21].

The following three aspects are considered in this paper to promote renewable energy power planning: 
(1) Central and local governments should be coordinated in renewable energy source planning. The central level of renewable energy power development planning should be strategic and directional planning, while the local renewable energy power supply planning should carry out the specific scientific planning within the frame and scope of central planning. Central planning and local planning must coordinate with each other to form a scientific and rational planning system. That is, on the one hand, it is important to enhance the attractiveness local renewable energy development; on the other hand, the construction scale and speed of local renewable energy sources should planned with reason to avoid renewable energy power generation projects being blindly launched.

(2) Renewable energy power planning, overall power planning and other power planning should be coordinated with each other. To achieve sustainable renewable energy development in the future, we need a flexible peaking power plan to speed up peaking power planning of fuel power generation and pumping storage power, actively develop coal-fired units with great peak performance, high parameters, large capacity and high efficiency. Under the premise of ecological environment protection, the construction of large hydropower stations with good regulation performance should speed up to meet the needs of the power system load, and promote the coordinated development of new energy power and supporting peaking power.

(3) Renewable energy source planning should be coordinated with regional power grid planning. With the further expansion of the scale of renewable energy power construction, renewable energy source development planning must be explicitly given priority regarding its status in the power system. For a large-scale new energy power base, planning schemes which promote consumption must be elaborated ahead of time to realize the coordinated development of renewable energy power and regional power grid planning.

\subsection{Improving Operation}

Practically, there is a big difference between Chinese and foreign renewable energy power. Foreign renewable energy power distribution is relatively dispersed and can be directly connected to distribution system. By contrast, distribution of China's renewable energy resources, especially wind energy, is concentrated in the northeast, north and northwest areas. It is large-scale and displays great distances from the load center, which makes it difficult regarding local consumptive power generation. The power structure in these areas is single and peaking capacity is limited. Ningxia Province, the selected study object of this paper, is located in the northwest in China. The ratio of the power which can be flexibly adjusted is comparatively low. The proportion of heating units that cannot be flexibly adjusted is larger in winter, resulting in the particular prominent problem of winter peaking. In view of the above problems, we must pay attention to the advantages of regional power grid interconnection and promote unified management and scheduling, scientific arrangement and operation mode of power grids for to secure regional renewable energy consumption. Specifically, this can improve the operation level of the regional power grid operation with regard to the following three aspects [22]:

(1) We should give full play to the advantages of scheduling systems to achieve coordination and cooperation at all levels. At present, China's power grid has formed a three level-scheduling system, dispatching on the state, province and regional levels. We should make full use of existing management modes, give full play to scheduling functions of all levels, achieve scheduling coordination at all levels, further enhance the interprovincial transmission capacity and realize cross-scheduling by optimizing regional power grid operation modes.

(2) We should learn from foreign advanced scheduling operation management technology and methods. By setting up special grid-dispatching operation research institutions and establishing renewable energy power analysis platforms, we can realize real-time tracking of the national and world's major countries' renewable energy power operation. On this platform, timely analysis and comparison could be carried out to further understand and grasp the latest trends 
of developments in renewable energy sources and advanced power grid dispatching operation experience, which will further enhance and improve renewable energy power dispatching operation management methods and means.

(3) A real-time scheduling monitoring network for renewable energy should be established. To realize the controllability and adjustment of renewable energy power generation, power grids must establish a dispatching and monitoring network, which covers the whole renewable energy electricity market to achieve grid interconnection. Research on renewable energy power prediction methods and technology would help to improve the precision of power prediction and enhance dispatching and control capabilities of power grids.

\subsection{Actively Promoting Renewable Energy Quota System}

The renewable energy quota system requires power companies to guarantee a certain proportion of the total purchased electricity generated from renewable energy [23]. Nowadays, Western developed countries have implemented renewable energy quota systems to promote development of the renewable energy industry. In the United States, the government began the implementation of the renewable energy quota system in early 1990s: Although the quota system has not been introduced at the federal level, most federal bills are related to the mandatory quota system. Even though there are differences regarding targets and means of implementation among all states, and the renewable energy utilization has greatly increased in states with and those without an implementation of quota system [24].

Some scholars conclude that the economy of renewable energy power generation will be greatly improved if the quota system is introduced into the field of renewable energy in China [25]. At the same time, the investment recovery period of renewable energy power generation projects will also be greatly reduced, and it can effectively solve the three major problems of renewable energy regarding power generation, grid connection and consumption. The core problem of the implementation of quota system is quota market transactions. At present, the green certificate trading system has been adopted as a means of trade in foreign countries, which can realize a balanced quota among different types of enterprises. Specifically, a government first approves of the renewable energy electricity production or consumption by the subject of quota responsibility. Then, it issues the corresponding green certificate, matching the quantity of renewable energy production and consumption with the corresponding quota. If the subject of quota responsibility was unable to complete the designated quota, it can purchase extra green certificates from those who have achieved a surplus over the quota in order to complete its own quota obligation [26].

Presently, the National Energy Bureau of China organizes experts and scholars to develop a "renewable energy quota management approach", which aims to introduce the restricted renewable energy power quota for power generation companies, power grid enterprises and local governments [27]. Firstly, power generation enterprises assume the obligations of renewable energy power generation; secondly, power grid enterprises bear purchase obligations; thirdly, consumers take the obligation of using renewable energy. The local government will guarantee the implementation of the quota scheme as the main administrative responsibility of renewable electricity consumption. Power grid enterprises need to become the main subject of quota implementation to guarantee the purchase of the quota. Renewable energy power generation enterprises need to become the main subject of the quota obligations to ensure the supply of green power. Since the implementation of quota systems involves multiple responsibility subjects and stakeholders, the system should be improved and perfect. Due to the core position of power grids in a quota system, the incentive measures to power grid enterprises have become the key to the successful implementation of quota systems.

\section{Conclusions}

On account of the current situation of renewable energy and power grids, this paper establishes a Markov prediction model based on error optimization from aspects of renewable energy development 
structure and proposes an optimization strategy of power supply structure. The validity of the model has been verified by an example in a certain area of Ningxia Province. From the study, we can draw the following conclusions:

(1) Through the establishment of a Markov prediction model based on error optimization and the prediction of renewable energy in Ningxia Province, we conclude that the model can accurately reflect structural trends of the renewable energy on-grid generation in the area. In comparison with the traditional Markov model, the fitting degree of the prediction results is higher, which verifies the effectiveness of the optimization model.

(2) By constructing a structure transfer model for Ningxia Province and predicting the power supply structure, it shows that the future supply structure will remain largely unchanged when regarding the equilibrium state of the area. Although the proportion of thermal on-grid power generation has declined gradually, due to the characteristics of the region's energy structure, the overall power structure that is mainly based on thermal power will change in the short term and thermal power will continue to occupy a large proportion of the on-grid power generation. Finally, the structure of the balance of on-grid generation is: $7.644 \%$ wind power, $0.634 \%$ solar photovoltaic, $2.111 \%$ hydropower and $89.611 \%$ thermal power.

(3) In order to improve the renewable energy grid electricity ratio and promote the coordinated development of renewable energy and traditional power grid, this paper has proposed optimization adjustment strategies for renewable energy power supply with regard to the three aspects of power grid development, power planning, scheduling and policy, which indicate direction for the development of renewable energy and power supply structure in the future.

Acknowledgments: This work was supported by Natural Science Foundation of China (Project No. 71471059). It was also funded by the Fundamental Research Funds for the Central Universities of China (2015XS41).

Author Contributions: All authors have conceived the idea of this paper. Xiaomin Xu performed simulations and wrote simulation sections. Dongxiao Niu initiated the project and gave much good research advice and guided the paper writing. Jinpeng Qiu performed all mathematical modeling in the manuscript. Peng Wang and Yanchao Chen contributed in writing the paper. All authors have read and approved the final manuscript.

Conflicts of Interest: The authors declare no conflict of interest.

\section{References}

1. Munoz, F.D.; Hobbs, B.F.; Watson, J.P. New bounding and decomposition approaches for MILP investment problems: Multi-area transmission and generation planning under policy constraints. Eur. J. Oper. Res. 2016, 248, 888-898. [CrossRef]

2. Jia., Y.W.; Gao, Y.; Xu, Z.; Wong, K.P.; Lai, L.L.; Xue, Y.; Dong, Z.Y.; Jill, D.J. Powering China's Sustainable Development with Renewable Energies: Current Status and Future Trend. Electr. Power Compon. Syst. 2015, 43, 1193-1204. [CrossRef]

3. Song, Y.H.; Zhang, C.; Tan, Z.F.; Shi, Q.S. Interregional Electric Power Planning Model Based on Sustainable Development of Wind Power. J. Energy Eng. 2015, 141, 1-10. [CrossRef]

4. The Notice about Wind Power Consumptive and Related Work in 2013 from National Energy Board. Available online: http://zfxxgk.nea.gov.cn/auto87/201303/t20130319_1587.htm (accessed on 16 February 2013).

5. Yu, X.X.; Zhang, P.; Liu, Z.Y.; Zuo, X.H.; Zhang, K.; Tian, Z.C. Wind power development and its consumptive ability in Beijing. Electr. Power Constr. 2015, 36, 49-54.

6. Xu, J.W.; Liu, Z.H. Research on the prediction and optimization of China's energy structure based on grey system theory. Ind. Saf. Environ. Prot. 2013, 39, 59-61.

7. Wang, J.Y. Wind power development in twelfth "Five-Year Plan". Energy Res. Utilization 2012, 3, 19-20.

8. Tao, Y.W.; Sun, M.; Wang, X.F. Research on China's energy demand forecasting based on improved BP neural network. J. Shanxi Univ. Financ. Econ. 2010, 32, 3-5.

9. Liu, D.H.; Yang, Y.P.; Yang, K.; Li, D.Q.; Yang, Z.P. Energy structure and pollutant emission prediction model and its application based on Markov chain. Electr. Power 2006, 39, 8-13. 
10. Parpas, P.; Webster, M. A stochastic multi-scale model for electricity generation capacity expansion. Eur. J. Oper. Res. 2014, 232, 359-374. [CrossRef]

11. He, M.; Yang, L.; Zhang, J.S.; Vittal, V. A Spatio-Temporal Analysis Approach for Short-Term Forecast of Wind Farm Generation. IEEE Trans. Power Syst. 2014, 29, 1611-1622. [CrossRef]

12. Xie, N.M.; Liu, S.F. Analysis of total energy consumption and structure prediction. Ind. Technol. Econ. 2009, $28,46-49$.

13. Huang, Y.S.; Wang, Z.M.; Zhang, Y.F. Markov prediction model and its application in the analysis of power consumption structure. In Proceedings of the Seventh Academic Exchange Conference of China Operations Research Society, Qingdao, China, 16-20 October 2004; Zhang, X.S., Ed.; Global-Link Publishing: Qingdao, China, 2004; pp. 489-453.

14. Lou, Y.J.; Ma, Y.M.; Han, L.F. Prediction of regional passenger transition structure based on Markov chain. Transp. Syst. Eng. Inf. 2012, 12, 1-5.

15. Wang, X.; Niu, D.X. Prediction of electric energy competitiveness based on Markov chain. Mod. Electr. Power 2004, 1, 94-97.

16. Zhang, X.C.; Niu, D.X.; Shen, W. Beijing city terminal energy structure prediction based on the Markov optimization model. Shaanxi Electr. Power 2008, 9, 6-9.

17. Gilat, A. MATLAB. An Introduction with Applications, 5th ed.; J. Wiley \& Sons: New York, NY, USA, 2015.

18. Zhu, C.Z. Further discussion on the power structure of China. Sino Glob. Energy 2008, 38, 2-10.

19. Li, G.L.; Zhu, H.; Lv, M. Evaluation of the importance of transportation channel nodes based on modified entropy weight and modified TOPSIS method. J. Shijiazhuang Railw. Univ. (Nat. Sci. Ed.) 2014, 1, 78-83.

20. Zhang, H.L. Research on the Development of Renewable Energy Resources in China. Master's Thesis, Jilin University, Jilin, China, 2014.

21. Mourmouris, J.C.; Potolias, C. A multi-criteria methodology for energy planning and developing renewable energy sources at a regional level: A case study Thassos, Greece. Energy Policy 2013, 52, 522-530. [CrossRef]

22. Chen, C.; Wang, F.; Zhou, B.; Chan, K.W.; Cao, Y.; Tan, Y. An interval optimization based day-ahead scheduling scheme for renewable energy management in smart distribution systems. Energy Convers. Manag. 2015, 106, 584-596. [CrossRef]

23. Freire, L.; Street, A.; Lima, D.A.; Barroso, L.A. A Hybrid MILP and Benders Decomposition Approach to Find the Nucleolus Quota Allocation for a Renewable Energy Portfolio. IEEE Trans. Power Syst. 2015, 30, 3265-3275. [CrossRef]

24. Xie, X.X.; Wang, T.; Ren, D.M. The latest development of American renewable energy quota system and its Enlightenment to China. China Energy 2012, 3, 33-37.

25. Ren, D.M. Discussion on some issues concerning the introduction of the quota system for renewable energy. Renew. Energy 2007, 29, 10-13.

26. Ren, D.M.; Xie, X.X. International experience in building a green certificate trading system for renewable energy. Renew. Energy 2013, 35, 12-15.

27. Ren, D.M. China's Renewable Portfolio Standards and Implementing Countermeasures. Autom. Electr. Power Syst. 2011, 35, 25-28.

(C) 2016 by the authors; licensee MDPI, Basel, Switzerland. This article is an open access article distributed under the terms and conditions of the Creative Commons Attribution (CC-BY) license (http://creativecommons.org/licenses/by/4.0/). 